\title{
Simulation and Analysis of DGA Analysis for Power Transformer Using Advanced Control Methods
}

\author{
Dr. Mihir K Patel \\ Assistant Professor, \\ Electrical Department, KITRC-Kalol, \\ Gujarat, India \\ mihirpatel@gmail.com
}

\begin{abstract}
In any power system or grid network transformer device use for power from one circuit to another circuit without changing the frequency with high efficiency levels. Due to number of usages Transformer protection is very important now a days for electric supply which is fault free, efficiency and to increase the transformer life cycle. This paper is a brief discussion about the concentration of different gases like $\mathrm{CO}$, $\mathrm{CO} 2, \mathrm{H} 2, \mathrm{C2H}, \mathrm{C2H} 4, \mathrm{C} 2 \mathrm{H} 2$ and $\mathrm{CH} 4$ related faults which is known as DGA analysis with the help of various classical techniques gives different conditions for the same sample unit. This paper presents MATLAB simulation of ANN and Machine learning based high accuracy design techniques for DGA analysis and the results are compared with the classical techniques like Key Gas Method, IEC Ratio method, Duval triangle Method and Rogers Ratio Method, but in this paper we have done only Duval triangle Method for Comparison using Matlab. The Simulation result of the proposed methods shows that overall DGA analysis using Machine learning algorithm is better than conventional Duval triangle method Performance.
\end{abstract} etc.

Key words: DGA, Duval Triangle, IEC Ratio, Rogers Ratio,

\section{INTRODUCTION}

The DGA is very important for transformer fault analysis for many years. In transformer we know that transformer oil is necessary part for insulating material and cooling purpose. Due to temperature and discharge in oil there are different gases like $\mathrm{C} 2 \mathrm{H} 6, \mathrm{C} 2 \mathrm{H} 4, \mathrm{C} 2 \mathrm{H} 2$ and $\mathrm{CH} 4$ are dissolved in oil which makes failure or breakdown of transformer oil. So for Normal and regulating performance of Power Transformer DGA analysis is most important and it will provides control in different type of fault conditions.

Firstly In1928 Buchholz has represents the method of fault diagnosis due to failure in transformer oil and gases which is dissolved in transformer oil. Due to that type of fault oil filled transformers realized that faults within a transformer would produce gases like $\mathrm{C} 2 \mathrm{H} 6, \mathrm{C} 2 \mathrm{H} 4, \mathrm{C} 2 \mathrm{H} 2$ and $\mathrm{CH} 4$ which will remain dissolved in oil. So that type of faults could be detected using analysis of gases dissolved in transformer oil. DGA analysis provides Monitoring and conditioning of transformer due to which it is easy to distinguish faults like PD (partial discharge), corona, thermal heating, and arcing.

For analyzing transformer performance and monitoring DGA is consider the best method and now a days it is useful because it has several advantages like:- Advanced warning of developing faults, Status checks on new and repaired units and it also provides Convenient scheduling of repairing and maintenance during fault or overload condition in transformer operation.

\author{
Dr. Alpesh M. Patel \\ Assistant Professor, \\ Electrical Department, GEC-Palanpur,
}

Gujarat, India
The use of DGA analysis in transformer will provides conditioning, monitoring, reliability and smooth operation of the oil filled transformer. Now in the next section we can discuss about DGA analysis methods used in transformer conditioning \& monitoring.

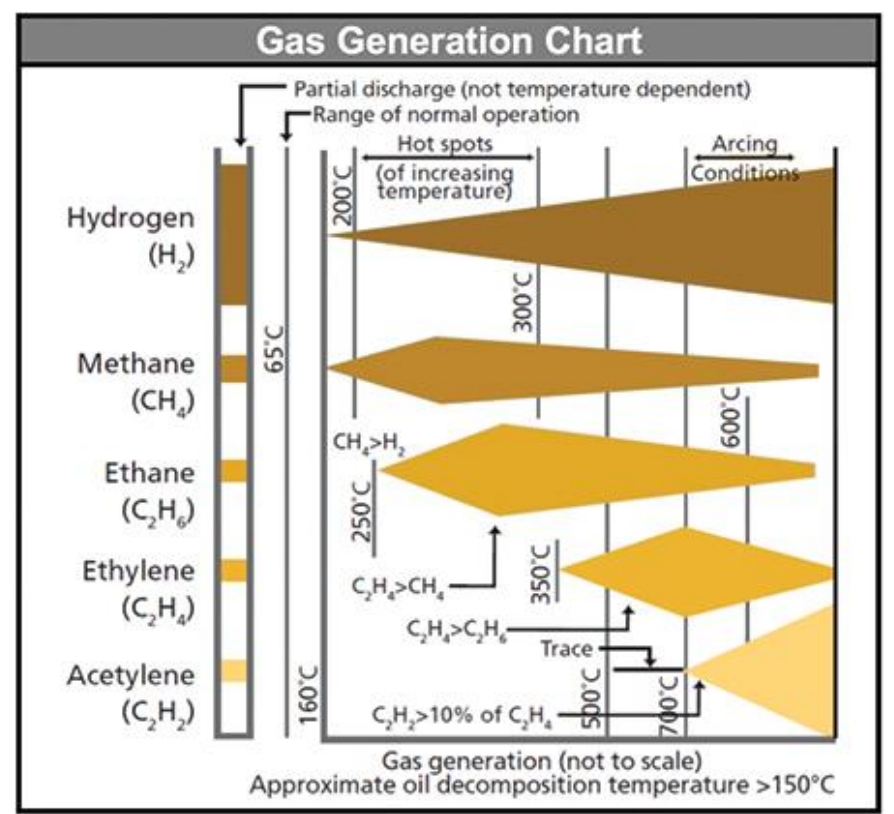

Fig. 1. Gas Generation Chart

Fault diagnosis of power transformers are required for the reasons:-

\section{Early detection of incipient faults:}

$\checkmark$ Avoid catastrophic outage

$\checkmark$ Provide basis for economic repair decision

\section{Efficiency and Management:}

$\checkmark$ Maintenance management based on measurement and trend analysis

$\checkmark \quad$ Ageing process and residual life under control

The main aim and important goal of monitoring and diagnostic during operation is continually operation of transformer and accurately diagnose the current condition and capability of transformer during any uncertain fault condition. This control will provides an alert just in time which easily provide maintenance action as and when required and remaining useful life of the equipment.

\section{SELECTION OF POWER TRANSFORMERS}

There are several basic considerations which must be included by the system engineer to select and design the best voltage which should supply power to both present and future loads economically. Some of these are: 


\section{A. Safety}

It is desirable to achieve high degree of safety of equipment and the personnel working on power transformers and the adjoining area.

\section{B. Reliability}

Power transformers are required to give high degree of reliability even in stipulated operating conditions during its stipulated service span of at least 40 years within working specifications. Power transformers are designed and manufactured to meet the reliability and offer trouble free service.

\section{Maintenance}

Power transformers regular maintenances are required to ensure reliable service throughout its life, put back a transformer which has broken-down into satisfactory working condition in a minimum possible life and also to keep the maintenance cost minimum. Thus transformer needs routine, corrective, preventive, proactive and emergency maintenances during its service life.

\section{Voltage regulation}

There are possibilities of recurring overloads and exceptional overloads in the working of power transformers. Thus under any overload conditions, it is desirable from the power transformers to maintain high voltage regulation to keep the output voltage constant.

\section{E. Initial investment}

Every utility choose to keep its economy at the priority. Thus it becomes necessary for every manufacturer to keep the cost of a power transformer in competitive limits and to keep other required specifications within the ranges.

\section{F. Simplicity in operation}

Each user develops his own operation needs appropriate to his requirements. Utilities also would want to operate power transformers with ease for the entire life of it. Thus simplicity in operation of power transformer becomes prime important.

\section{G. The overall system economics}

Starting from design, manufacturing, installation, maintenance, repair and overhauls (if needed) involve economy. Though continuity of power supply is needed from any transformer. The total cost of a transformer can be considered as the assured annuity for the estimated life of the transformer obtained from a capital sum invested.

\section{NECESSITY OF FAULT DIAGNOSIS}

Generally speaking, the term observance describes a basic parameter measure with threshold alarms. The term medicine indicates the addition of refined analysis, there are a spread of tools out there to judge the condition of transformers. They will be separated into ancient DGA diagnostic strategies that have seen widespread use for transformer from so many different conditions during nontraditional strategies that vary from strategies that are setting out to be wont to strategies that are still within the analysis stage. Fault diagnosis of power transformers are required for the reasons:

\section{Early detection of incipient faults:}

- Avoid catastrophic outage

- Provide basis for economic repair decision
II. Efficiency and Management:

- Maintenance management based on measurement and trend analysis

- Ageing process and residual life under control

The main aim and important goal of monitoring and diagnostic during operation is continually operation of transformer and accurately diagnose the current condition and capability of transformer during any uncertain fault condition. This control will provides an alert just in time which easily provide maintenance action as and when required and remaining useful life of the equipment.

\section{BENEFITS OF FAULT DIAGNOSIS}

Some of the benefits of the fault diagnosis of any equipment in general are as follows:

1. Within Time Measurements of all parameters

2. Sensing of the fault gases in transformer operation

3. Predictive decision making for fault

4. Reducing the outages of parameters

5. Accurate, predictable and reliable maintenance schedules for transformers

6. Prevention of major failure and destruction of protection equipment

7. Reduced maintenance cost

8. The results provide a quality control feature, limiting the probability of destructive failures

\section{Types of Faults}

Due to DGA analysis in transformer there are different types of fault identification is done through proper analysis. According to the variation of Gases value of $\%$ variation will effects the Discharge and Thermal faults which are classified as given below:-

Partial Discharge (PD) - The corona discharge in the transformer oil will creates PD effects in the oil filled transformer and energy discharge also occurs.

Discharges of Low Energy (D1) - This fault will occurs in oil due to the large carbonized punctures or carbon particles in oil, which affects the performance of oil/Paper.

Discharges of High Energy (D2) - This fault will occurs in oil due to extensive destruction and carbonization of oil in the transformer.

Thermal Fault (T1) - This type of fault will occurs below $300{ }^{\circ} \mathrm{C}$ in oil.

Thermal Fault (T2) - This type of fault will occurs above $300{ }^{\circ} \mathrm{C}$ \& below $700{ }^{\circ} \mathrm{C}$ in oil.

Thermal Fault (T3) - This type of fault will occurs above $700{ }^{\circ} \mathrm{C}$ in oil.

\begin{tabular}{|c|l|}
\hline Abbreviations & Descriptions \\
\hline PD & Partial Discharges \\
\hline D1 & Discharges of Low Energy \\
\hline D2 & Discharges of High Energy \\
\hline T1 & Thermal Fault, $\mathrm{t}<300^{\circ} \mathrm{C}$ \\
\hline T2 & Thermal Fault, $300^{\circ} \mathrm{C}<\mathrm{t}<700^{\circ} \mathrm{C}$ \\
\hline T3 & Thermal Fault, $\mathrm{t}>700^{\circ} \mathrm{C}$ \\
\hline
\end{tabular}

Fig. 2. Types of Fault 


\section{Dissolved Gas ANALYSis (DGA)}

It is the helpful for the detection of early faults and most used technique currently every day. DGA involves following steps [1]. First step is to take the Sample of oil from the unit and extract the dissolved gases from oil. Second step is to sight the gas concentrations and analyse by diagnostic strategies to search out the faults in oil.

Most of the DGA diagnostic tools in use these days is found within the IEEE C57.104 standard or IEC 60599 guides. Supported these 2 standards used in different national and international to solely discuss those tools found within the IEEE and IEC guides.

\section{DGA Analysis Methods}

\section{Conventional Methods:-}

$\checkmark \quad$ Key Gas Method

$\checkmark$ Doernenburg Ratio Method

$\checkmark$ Rogers Ratio Method (RRM)

$\checkmark$ Duval Triangle Method

II. Machine Learning Methods:-

$\checkmark$ Fuzzy Logic Method

$\checkmark$ ANN Method

$\checkmark$ SVM Method

$\checkmark$ Basient Method

\section{Key Gas Method}

The Key Gas method is based on the quantity of fault gases which are released from the insulating oil at varying temperatures in the transformer. Figure 3 summarizes the key gases and their fault indications.

\begin{tabular}{|c|c|c|}
\hline \multicolumn{3}{|c|}{ Key Gas Method (IEEE Std. C57.104-2008) } \\
\hline Key Gas & Fault Type & Typical Proportions of Generated Combustible Gases \\
\hline $\mathrm{C}_{2} \mathrm{H}_{4}$ & Thermal oil & $\begin{array}{l}\text { Mainly } \mathrm{C}_{2} \mathrm{H}_{4} ; \text { Smaller proportions of } \mathrm{C}_{2} \mathrm{H}_{6}, \mathrm{CH}_{4} \text {, and } \mathrm{H}_{2 ;} \\
\text { Traces of } \mathrm{C}_{2} \mathrm{H}_{2} \text { at very high fault temperatures }\end{array}$ \\
\hline $\mathrm{co}$ & Thermal oil and cellulose & $\begin{array}{l}\text { Mainly CO; Much smaller quantities of hydrocarbon; } \\
\text { Gases in same proportions as thermal faults in oil alone }\end{array}$ \\
\hline $\mathrm{H}_{2}$ & Electrical Low Energy Partial Discharge & Mainly $\mathrm{H}_{2}$; Small quantities of $\mathrm{CH}_{4}$; Traces of $\mathrm{C}_{2} \mathrm{H}_{4}$ and $\mathrm{C}_{2} \mathrm{H}_{6}$ \\
\hline $\mathrm{H}_{2} \& \mathrm{C}_{2} \mathrm{H}_{2}$ & Electrical High Energy (arcing) & $\begin{array}{l}\text { Mainly } \mathrm{H}_{2} \text { and } \mathrm{C}_{2} \mathrm{H}_{2} ; \text { Minor traces of } \mathrm{CH}_{4}, \mathrm{C}_{2} \mathrm{H}_{4} \text {, and } \mathrm{C}_{2}, \mathrm{H}_{6} \text {; } \\
\text { Also collose is involved }\end{array}$ \\
\hline
\end{tabular}

Fig. 3. Key Gas Method

Figure 4 indicates these key gases and their relative proportions to indicate the four general types of faults.

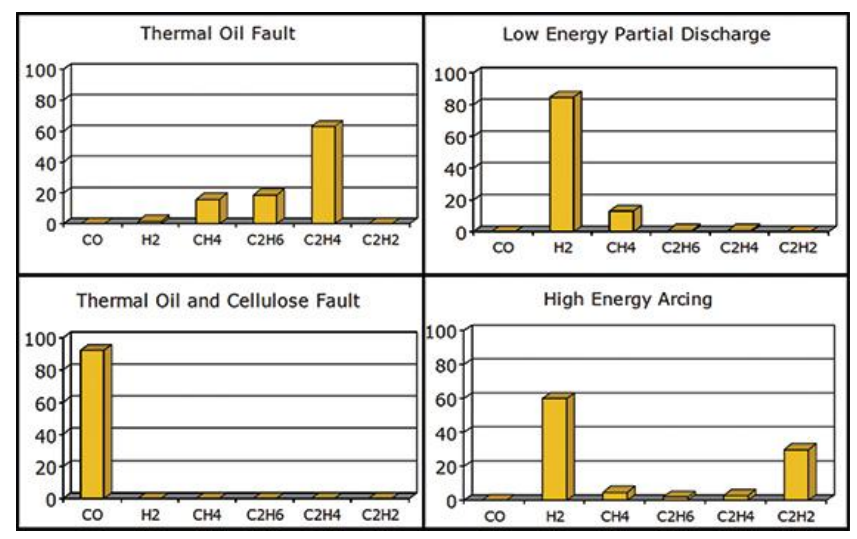

Fig. 4. Key Gas Proportions

\section{Doernenburg Ratio Method (DRM)}

The Doernenburg method can be found in the IEEE C57.104-1991 guide as shown in Figure 5. When this criterion is met, there are four possible ratios that can be calculated if they contain the key gas of concern. Figure 7 shows the proposed fault diagnostics is based on the ranges of the four ratios.

\begin{tabular}{|l|c|}
\hline \multicolumn{2}{|c|}{ Concentration of Dissolved Gas } \\
\hline Key Gas & $\begin{array}{c}\text { L1 Concentrations } \\
\text { (ppm) }\end{array}$ \\
\hline Hydrogen $\left(\mathrm{H}_{2}\right)$ & 100 \\
\hline Methane $\left(\mathrm{CH}_{4}\right)$ & 120 \\
\hline Carbon Monoxide (CO) & 350 \\
\hline Acetylene $\left(\mathrm{C}_{2} \mathrm{H}_{2}\right)$ & 35 \\
\hline Ethylene $\left(\mathrm{C}_{2} \mathrm{H}_{4}\right)$ & 50 \\
\hline Ethane $\left(\mathrm{C}_{2} \mathrm{H}_{6}\right)$ & 65 \\
\hline
\end{tabular}

Fig. 5. DRM method analysis

\section{Rogers Ratio Method (RRM)}

The Rogers Ratio method evolved from the Doernenburg method and is used exactly the same way, but instead of needing significant concentrations of the key gases, the RRM can be used when the concentrations exceed the values listed in Figure 5, Values for the three gas ratios, corresponding to suggested diagnostic cases, are shown in Figure 6.

\begin{tabular}{|c|l|l|l|l|}
\hline \multicolumn{5}{|c|}{ Ratios for Key Gases - Rogers Ratios Method } \\
\hline Case & $\begin{array}{c}\text { Ratio 2 (R2) } \\
\mathrm{C}_{2} \mathrm{H}_{2} / \mathrm{C}_{2} \mathrm{H}_{4}\end{array}$ & $\begin{array}{c}\text { Ratio 1 (R1) } \\
\mathrm{CH} / \mathrm{H}_{2}\end{array}$ & $\begin{array}{c}\text { Ratio 3 (R3) } \\
\mathrm{C}_{2} \mathrm{H}_{4} / \mathrm{C}_{2} \mathrm{H}_{6}\end{array}$ & \multicolumn{1}{|c|}{ Suggested Fault Type } \\
\hline 0 & $<0.01$ & $<0.1$ & $<1.0$ & Normal \\
\hline 1 & $\geq 1.0$ & $\geq 0.1,<0.5$ & $\geq 1.0$ & Discharge of low energy \\
\hline 2 & $\geq 0.6,<3.0$ & $\geq 0.1,<1.0$ & $\geq 2.0$ & Discharge of high energy \\
\hline 3 & $<0.01$ & $\geq 1.0$ & $<1.0$ & Thermal fault, low temp $<300^{\circ} \mathrm{C}$ \\
\hline 4 & $<0.1$ & $\geq 1.0$ & $\geq 1.0,<4.0$ & Thermal fault, $<700^{\circ} \mathrm{C}$ \\
\hline 5 & $<0.2$ & $\geq 1.0$ & $\geq 4.0$ & Thermal fault, $>700^{\circ} \mathrm{C}$ \\
\hline
\end{tabular}

Fig. 6. RRM Method analysis

\section{DUVAL TRIANGLE METHOD FOR DISSOLVED GAS ANALYSIS}

In the 1970s it was identified that the gas ratio methods has a disadvantage that some DGA results may not fall within the ratio codes and hence the diagnosis could remain unresolved. To overcome this problem, a graphical method was proposed by Duval in 1974. Within the triangle there are six (6) potential fault zones covering partial discharges, electrical faults that correspond to the increasing energy levels of gas formation, as shown in Figure.7

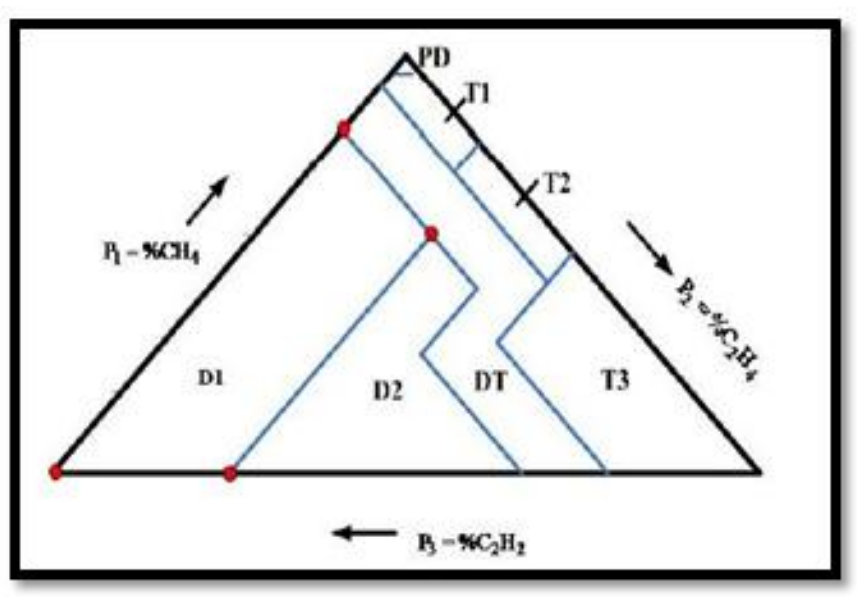

Fig. 7. Duval Triangle Method representation of three types of fault zones 
These gas concentrations are calculated and then plotted along the three sides of a triangle diagram using the following ratios:

- $\% \mathrm{CH}_{4}=\left(\mathrm{CH}_{4} / \mathrm{CH}_{4}+\mathrm{C}_{2} \mathrm{H}_{2}\right) \times 100$

- $\% \mathrm{C}_{2} \mathrm{H}_{4}=\left(\mathrm{C}_{2} \mathrm{H}_{4} / \mathrm{CH}_{4}+\mathrm{C}_{2} \mathrm{H}_{4}+\mathrm{C}_{2} \mathrm{H}_{2}\right) \times 100$

- $\% \mathrm{C}_{2} \mathrm{H}_{2}=\left(\mathrm{C}_{2} \mathrm{H}_{2} / \mathrm{CH}_{4}+\mathrm{C}_{2} \mathrm{H}_{4}+\mathrm{C}_{2} \mathrm{H}_{2}\right) \times 100$

TABLE I. DUVAL TRIANGLE DETECTABLE POSSIBLE FAULTS

\begin{tabular}{|c|c|c|}
\hline Symbol & Fault Code & Examples \\
\hline PD & Partial Discharge & $\begin{array}{l}\text { Cold plasma } \\
\text { discharges(corona), voids } \\
\text { (or) Gas Bubbles }\end{array}$ \\
\hline D1 & Discharge of low Energy & $\begin{array}{l}\text { Partial Discharges of } \\
\text { sparking type like } \\
\text { carbonized punctures, } \\
\text { pinholes. }\end{array}$ \\
\hline D2 & Discharge of High Energy & Discharges in oil or paper, \\
\hline $\mathrm{T} 1$ & Thermal Fault $<300^{\circ} \mathrm{C}$ & $\begin{array}{l}\text { Evidenced by paper } \\
\text { turning brownish }\end{array}$ \\
\hline $\mathrm{T} 2$ & Thermal fault $300^{\circ} \mathrm{C}-700^{\circ} \mathrm{C}$ & $\begin{array}{l}\text { formation of carbon } \\
\text { particles, } \\
\text { Carbonization of paper }\end{array}$ \\
\hline DT & $\begin{array}{l}\text { Combination of Electrical } \\
\text { and Thermal }\end{array}$ & $\begin{array}{l}\text { Discharges of low energy, } \\
\text { pinholes }\end{array}$ \\
\hline
\end{tabular}

From a percentage of $\mathrm{P} 1$ (such as point $\mathrm{D}$ ) draw a parallel line to BC, Hence Figure- 8 shows sample of point shown in a triangle for above example of gases concentrations.

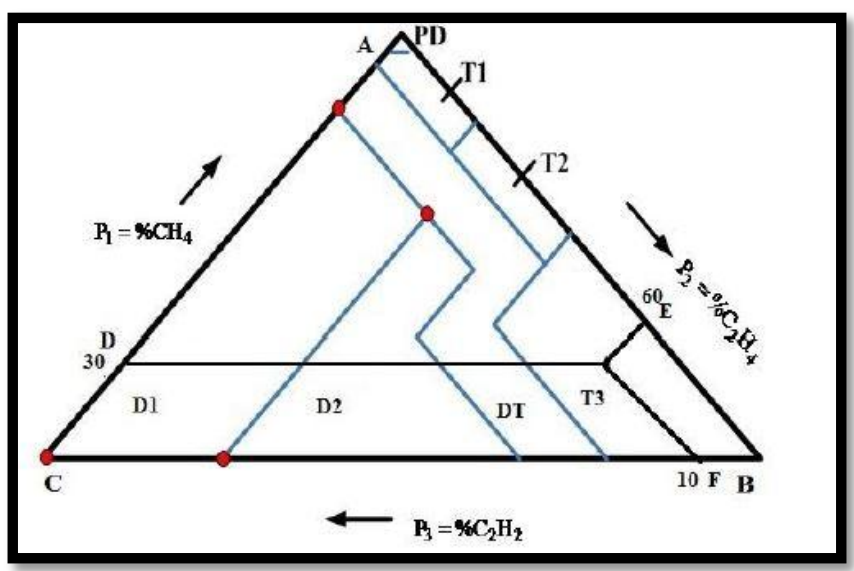

Fig. 8. Sample of fault zone point showed in a Duval Triangle Method

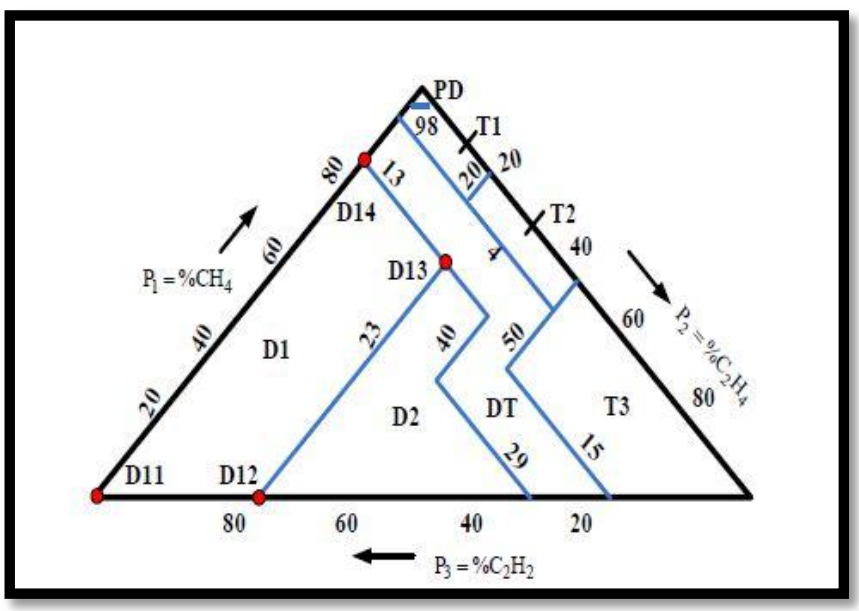

Fig. 9. Different fault zone coordinates representation of Duval Triangle

\section{Duval Triangle Fault Zones Coordinates}

To focus distinctive zones of Duval Triangle, we need to characterize a polygon for each one zone. As indicated in Figure-9 Approximately 200 plus inspected fault cases in service were used to develop the Triangle.

TABLE II. DUVAL TRIANGLE TRIANGULAR COORDINATES

\begin{tabular}{|c|c|c|c|c|}
\hline Area & Points & $\% \mathrm{CH}_{4}$ & $\% \mathrm{C}_{2} \mathrm{H}_{4}$ & $\% \mathrm{C}_{2} \mathrm{H}_{2}$ \\
\hline \multirow[t]{4}{*}{ D1 } & D11 & 0 & 0 & 1 \\
\hline & D12 & 0 & 0.23 & 0.77 \\
\hline & D13 & 0.64 & 0.23 & 0.13 \\
\hline & D14 & 0.87 & 0 & 0.13 \\
\hline \multirow[t]{5}{*}{ D2 } & D21 & 0 & 0.23 & 0.77 \\
\hline & D22 & 0 & 0.71 & 0.29 \\
\hline & D23 & 0.31 & 0.40 & 0.29 \\
\hline & D24 & 0.47 & 0.4 & 0.3 \\
\hline & D25 & 0.64 & 0.23 & 0.13 \\
\hline \multirow[t]{8}{*}{ DT } & $\mathrm{DT}_{1}$ & 0 & 0.71 & 0.29 \\
\hline & $\mathrm{DT}_{2}$ & 0 & 0.85 & 0.5 \\
\hline & $\mathrm{DT}_{3}$ & 0.35 & 0.5 & 0.15 \\
\hline & $\mathrm{DT}_{4}$ & 0.46 & 0.5 & 0.04 \\
\hline & $\mathrm{DT}_{5}$ & 0.96 & 0 & 0.04 \\
\hline & $\mathrm{DT}_{6}$ & 0.87 & 0 & 0.13 \\
\hline & $\mathrm{DT}_{7}$ & 0.47 & 0.4 & 0.13 \\
\hline & $\mathrm{DT}_{8}$ & 0.31 & 0.4 & 0.29 \\
\hline \multirow[t]{5}{*}{$\mathrm{T}_{1}$} & $\mathrm{~T}_{11}$ & 0.76 & 0.2 & 0.04 \\
\hline & $\mathrm{T}_{12}$ & 0.8 & 0.2 & 0.0 \\
\hline & $\mathrm{T}_{13}$ & 0.98 & 0.02 & 0.0 \\
\hline & $T_{14}$ & 0.98 & 0.02 & 0.02 \\
\hline & $\mathrm{T}_{15}$ & 0.96 & 0.0 & 0.04 \\
\hline \multirow[t]{4}{*}{$\mathrm{T}_{2}$} & $\mathrm{~T}_{21}$ & 0.46 & 0.5 & .04 \\
\hline & $\mathrm{T}_{22}$ & 0.5 & 0.5 & 0 \\
\hline & $\mathrm{T}_{23}$ & 0.8 & 0.2 & 0 \\
\hline & $\mathrm{T}_{24}$ & 0.76 & 0.2 & 0.04 \\
\hline \multirow[t]{4}{*}{$\mathrm{T}_{3}$} & $\mathrm{~T}_{31}$ & 0 & 0.85 & 0.15 \\
\hline & $\mathrm{T}_{32}$ & 0 & 1 & 0 \\
\hline & $\mathrm{T}_{33}$ & 0.5 & 0.5 & 0 \\
\hline & $\mathrm{T}_{34}$ & 0.35 & 0.5 & 0.15 \\
\hline \multirow[t]{3}{*}{ PD } & $\mathrm{PD}_{1}$ & 0.98 & 0.02 & 0 \\
\hline & $\mathrm{PD}_{2}$ & 1 & 0 & 0 \\
\hline & $\mathrm{PD}_{3}$ & 0.98 & 0 & 0.02 \\
\hline
\end{tabular}

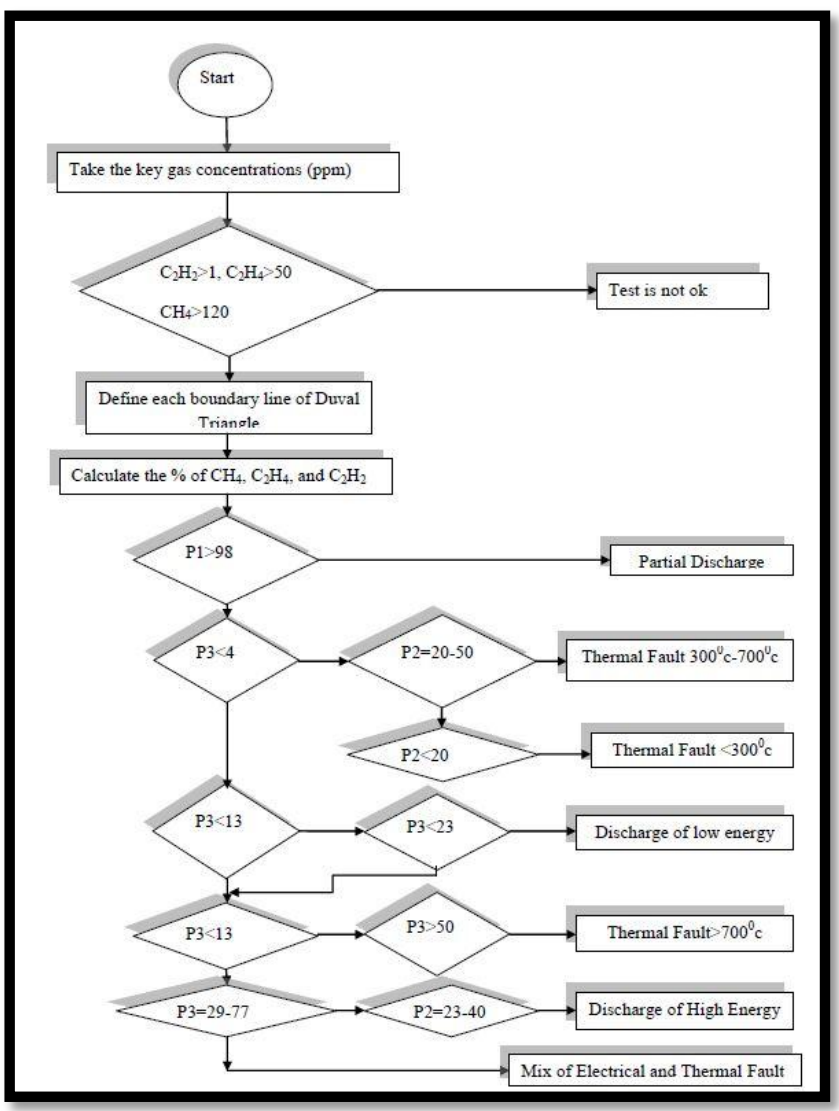

Fig. 10. Flow chart of Identification of $\% \mathrm{CH} 4, \% \mathrm{C} 2 \mathrm{H} 4$ and $\% \mathrm{C} 2 \mathrm{H} 2$ gases present in Transformer oil using Duval Triangle Method 


\section{Software Implementation to Duval Triangle}

To implement the Duval Triangle a MATLAB program is developed, it gives visual display of all type of fault zones with different color.

\section{Result and Discussions}

By taking the same sample input data used in key gas method shown in Table-1, Duval Triangle Method gives result in shown in Figure-11.

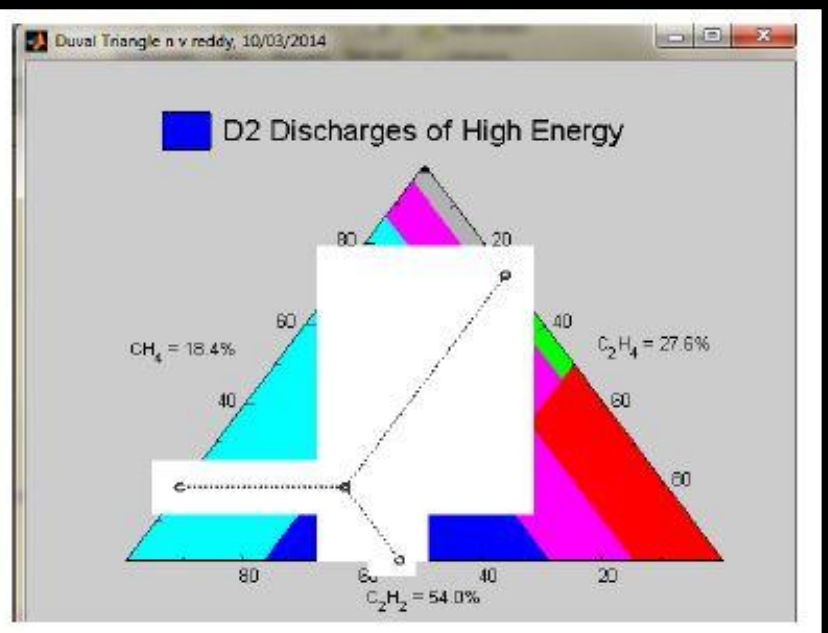

Fig. 11. Result window of Duval Triangle Method using MATLAB

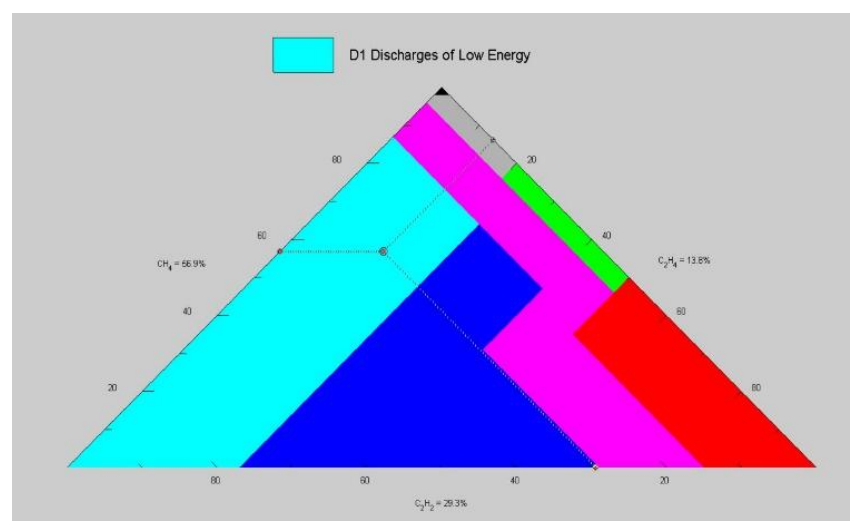

Fig. 12. Discharge of Low Energy

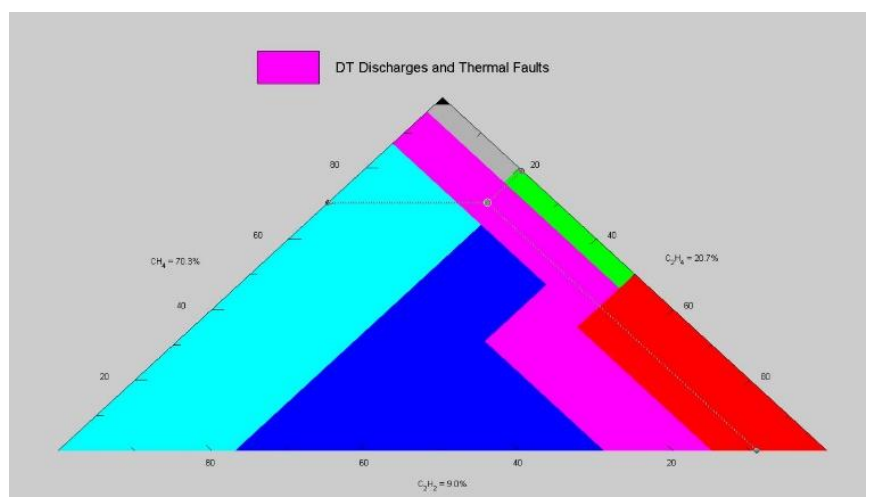

Fig. 13. Discharge of Thermal Limits

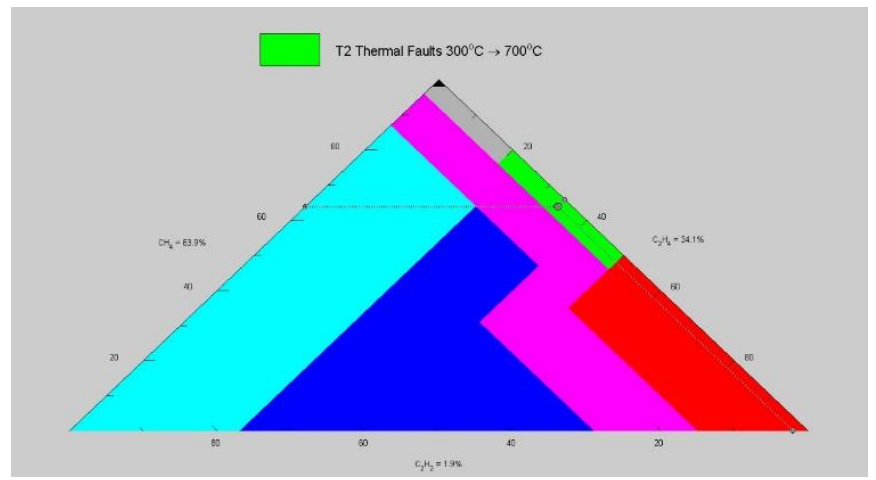

Fig. 14. Thermal Limits Increased from $300{ }^{\circ} \mathrm{c}$ to $700{ }^{\circ} \mathrm{C}$

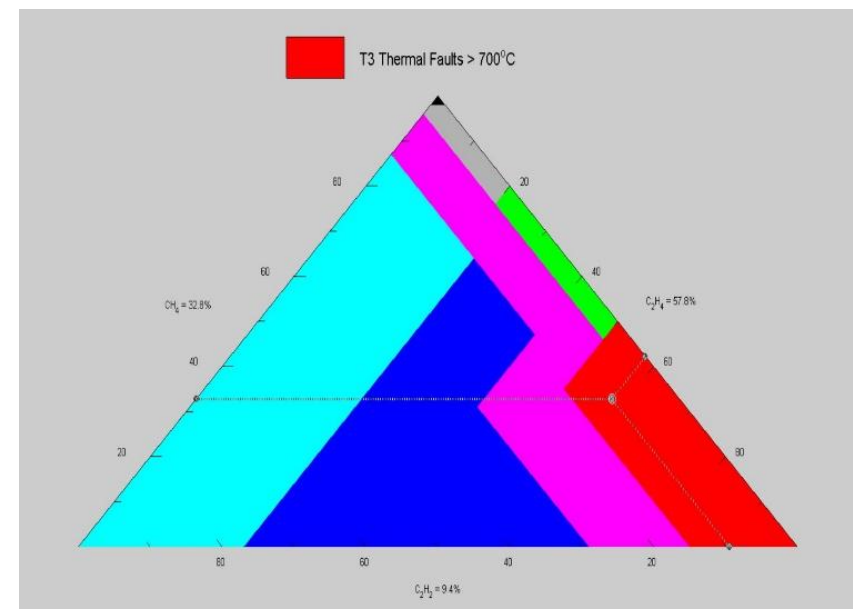

Fig. 15. Thermal Fault Condition

\begin{tabular}{|c|c|c|c|c|}
\hline $\begin{array}{l}\text { Sr. } \\
\text { No. }\end{array}$ & $\begin{array}{l}\text { CH4 } \\
\text { value } \\
(\%)\end{array}$ & $\begin{array}{l}\text { C2H4 } \\
\text { value } \\
(\%)\end{array}$ & $\begin{array}{l}\text { C2H2 } \\
\text { value } \\
(\%)\end{array}$ & Type of Fault \\
\hline 1. & $56.9 \%$ & $13.8 \%$ & $29.3 \%$ & $\begin{array}{l}\text { Discharge of Low } \\
\text { energy }\end{array}$ \\
\hline 2. & $70.3 \%$ & $20.7 \%$ & $9.0 \%$ & $\begin{array}{l}\text { Discharge of } \\
\text { Thermal Limits }\end{array}$ \\
\hline 3. & $63.9 \%$ & $34.1 \%$ & $19 \%$ & $\begin{array}{l}\text { Thermal Fault } 300 \mathrm{c} \\
\text { to } 700 \circ \mathrm{C}\end{array}$ \\
\hline 4. & $32.8 \%$ & $\mathbf{5 7 . 8 \%}$ & $9.4 \%$ & Thermal Fault above \\
\hline
\end{tabular}

From the simulation result of Duval triangle we can say that the value of Gases $\mathrm{CH} 4, \mathrm{C} 2 \mathrm{H} 2$ and $\mathrm{C} 2 \mathrm{H} 4$ has been changes for different \% value according to that the different types of fault conditions identified like Low/High energy discharge and Temperature faults.

The different types of fault has been identified using Duval Triangle but the only limitation with this conventional method is that we can't make different variable parameters control like advanced control methods like AI techniques and Machine learning algorithms. 
The Duval Triangle justify the fault conditions with changes in $\mathrm{CH} 4, \mathrm{C} 2 \mathrm{H} 2$ and $\mathrm{C} 2 \mathrm{H} 4$ Dissolved gases in Transformer oil.

\section{Machine Learning}

A branch of artificial intelligence, concerned with the design and development of algorithms that allow computers to evolve behaviors based on empirical data. As intelligence requires knowledge, it is necessary for the computers to acquire knowledge.

\section{Testing}

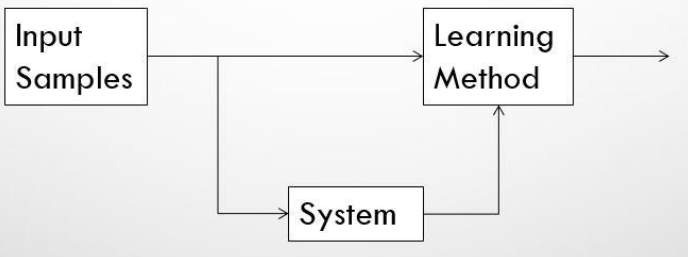

Training

Fig. 16. Learning system model

\section{ANN Implementation for DGA Analysis}

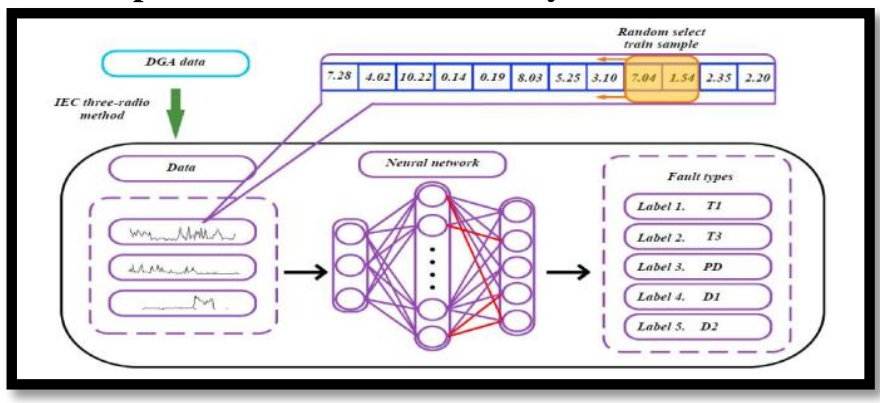

Fig. 17. Power transformer fault diagnosis using ANN

In this project we have a tendency to plan a machine learning-based approach for fault identification of power electrical device. The planned technique used the synthetic neural network (ANN) to construct the fault identification model. For several years there was no on paper sound rule for coaching multi-layer ANN, and thus, the applications of ANN were severely restricted. A two-layer feed-forward network is shown in Fig. It consists of variety of neurons connected by links divided into 2 layers.

A set of inputs is applied from outside or from previous layer. Every of those is increased by a corresponding weight w. The add of the weighted inputs and therefore the bias .b. forms the input .n. to the transfer/activation operate " $F$ ". Neurons could use any differentiable, monotonic increasing transfer functions to get their outputs.

\section{Simulation Results of ANN Techniques}

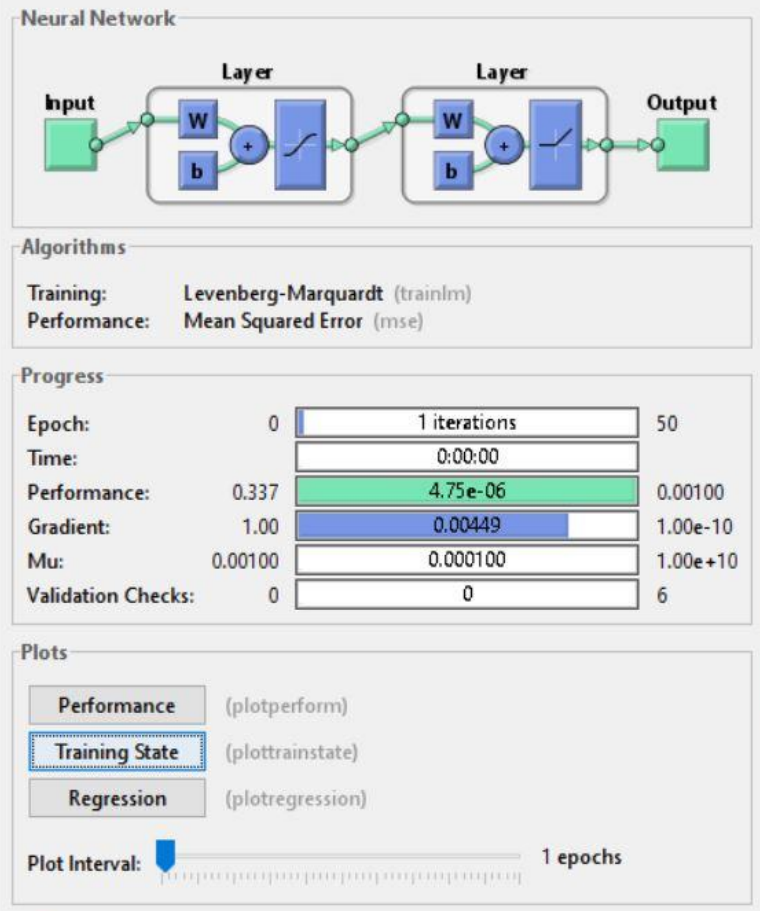

Opening Performance Plo1

Stop Training Cancel

Fig. 18. ANN Implementation for Case Study-I

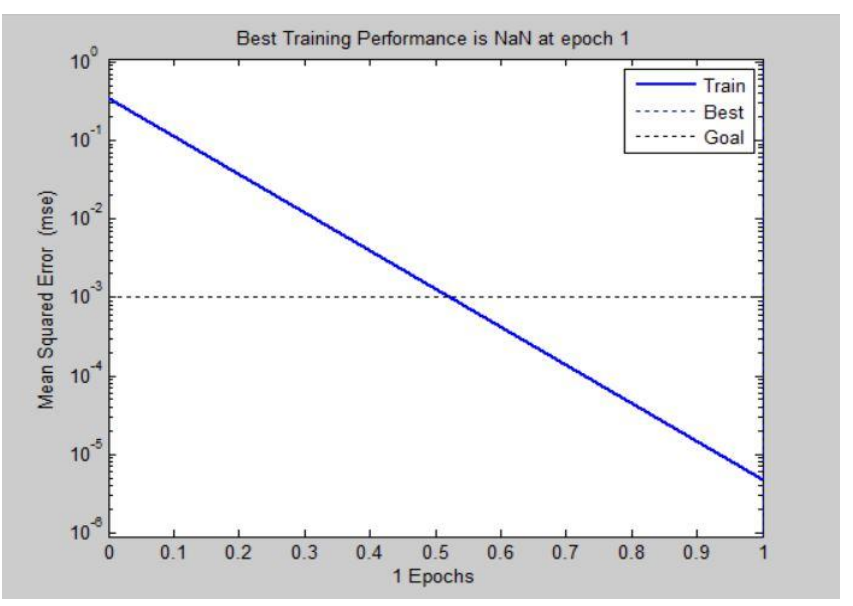

Fig. 19. Performance Analysis of DGA for Case Study-I

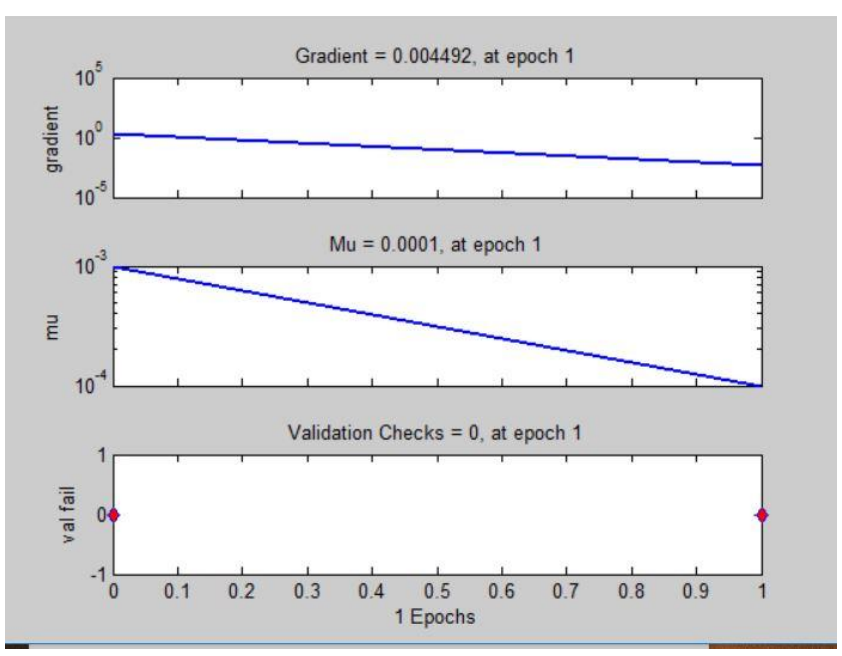

Fig. 20. Parameters Variation for Case Study-I 
TABLE III. PARAMETERS FOR ANN METHOD

\begin{tabular}{|c|c|}
\hline Input & {$[\% \mathrm{CH} 4 \% \mathrm{C} 2 \mathrm{H} 6 \% \mathrm{C} 2 \mathrm{H} 2]$} \\
\hline Output & Faults $[1234567]$ \\
\hline Maximum Input & $100 \%, 100 \%, 100 \%$ \\
\hline Maximum Output & $0.1 \%, 0.1 \%, 0.1 \%$ \\
\hline Training Function & Levenberg-Marquardt \\
\hline Epochs & 50 \\
\hline Performance & Mean Square Errors (MSE) \\
\hline Number of Neurons & 2 \\
\hline
\end{tabular}

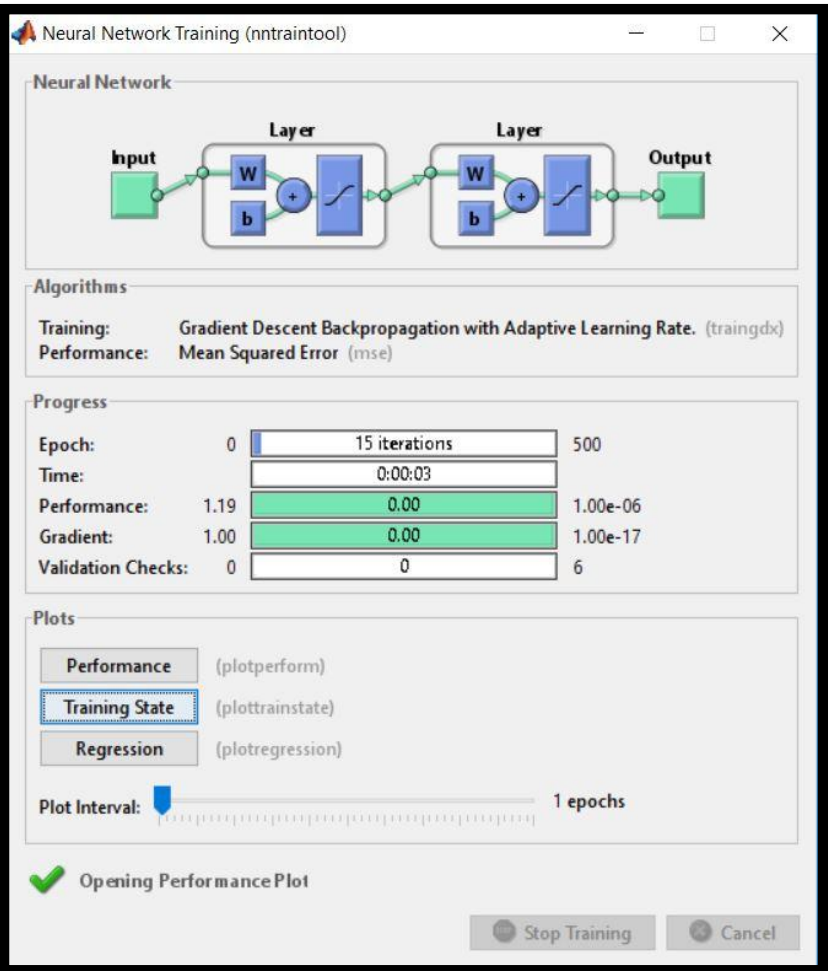

Fig. 21. ANN Implementation for DGA Analysis Case Study-II

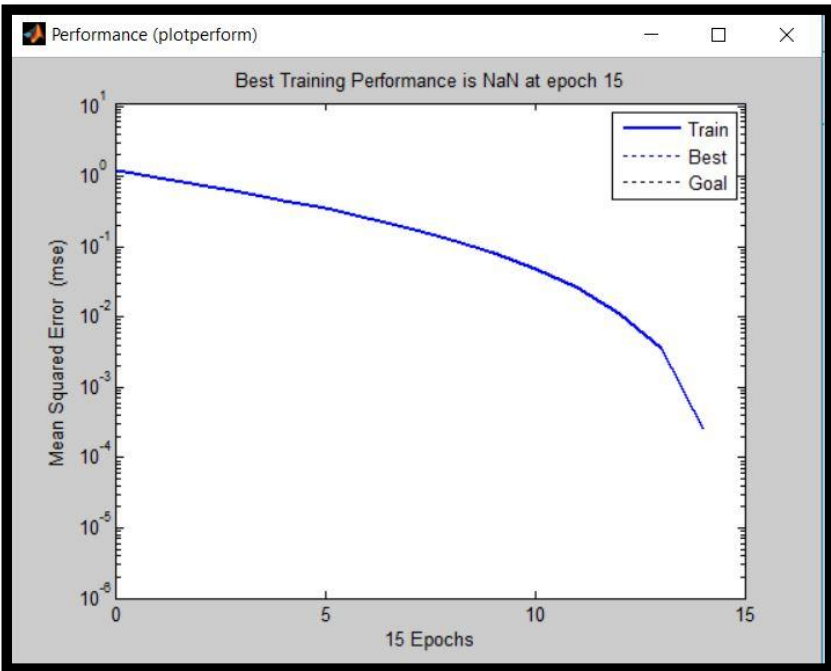

Fig. 22. Validation performance chart for Case Study-II
$\Delta \mathrm{T}$

Training State (plottrainstate)

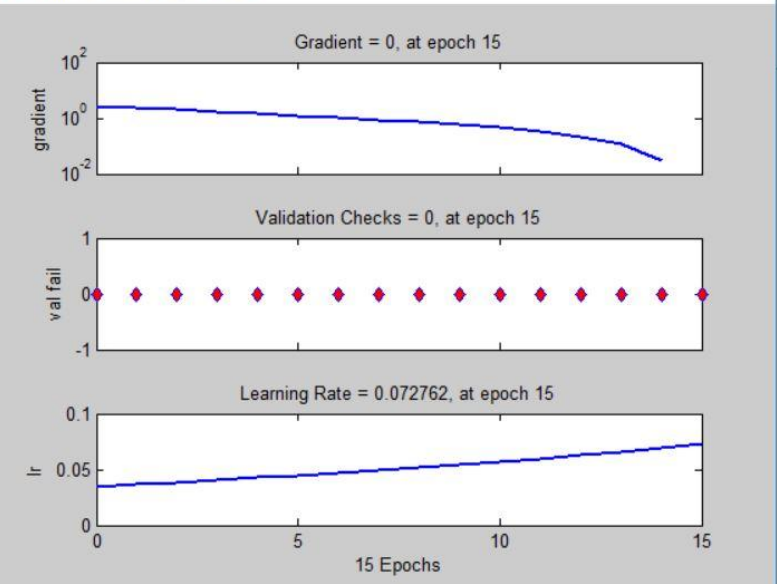

Fig. 23. Mu and Gradient plot for Case Study-II

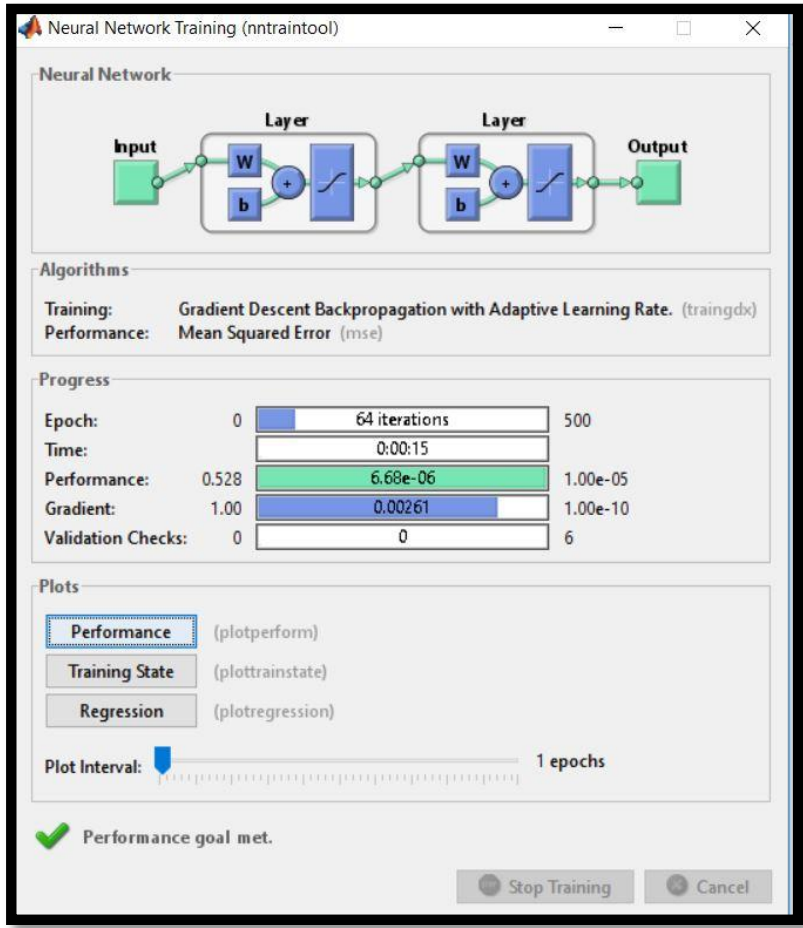

Fig. 24. ANN Implementation for DGA Analysis

Case Study-III

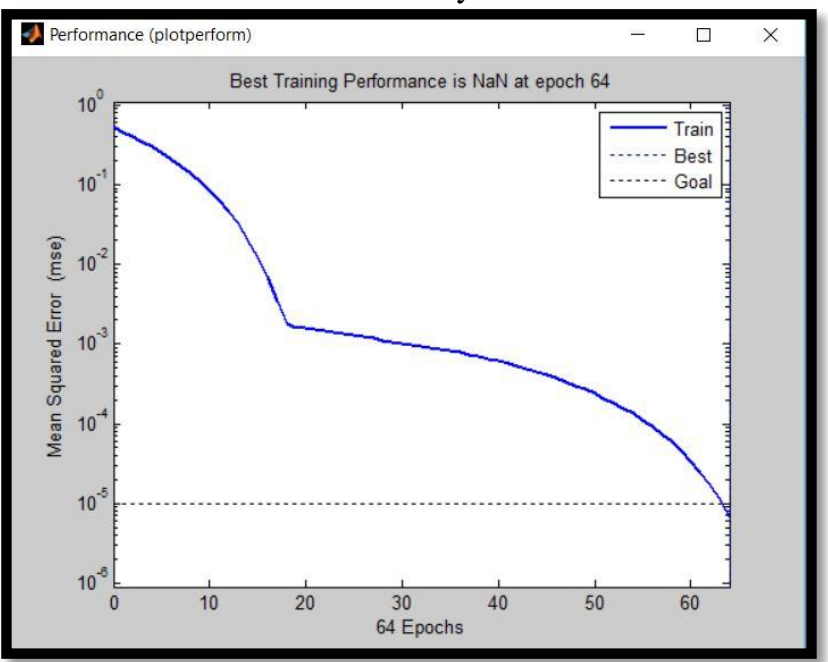

Fig. 25. Validation performance chart for Case Study-III 


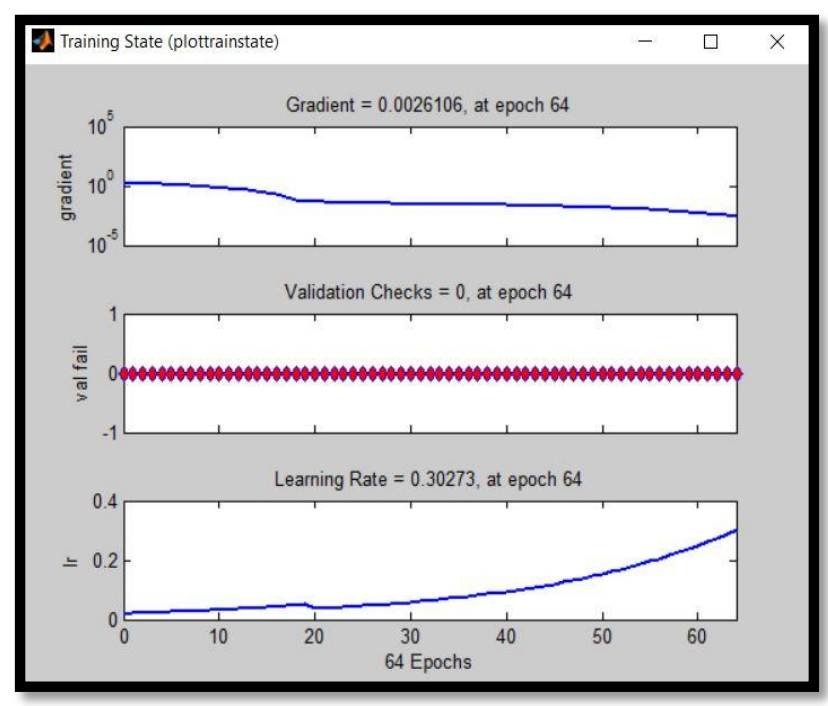

Fig. 26. Mu and Gradient plot for Case Study-III

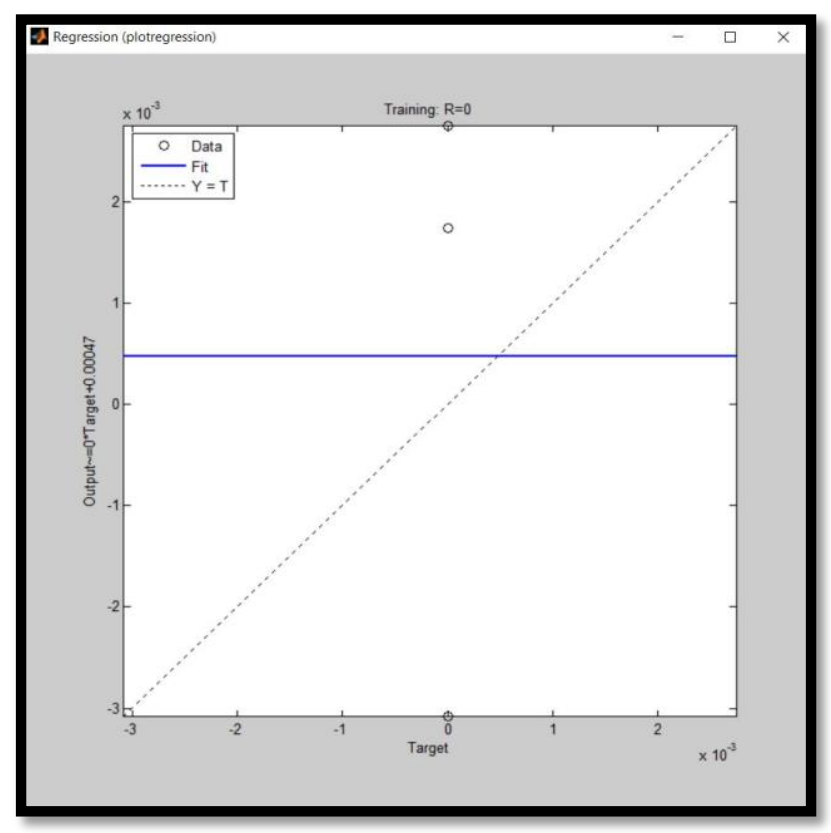

Fig. 27. Target plots for Case study-III

\section{Summary of Simulation Results}

- Simulated results with artificial neural network approaches on Duval triangle are compared with fault diagnosis Simulation results.

- It is found that artificial neural network approach will give better results than actual fault diagnosis report results using Duval Triangle. Further it is it is observed that ANN provides fast and accurate results as compared to Duval result.

- The main benefit is that using ANN technique we can perform the DGA analysis for different conditions and different parameters, it has wide range of applications.

\section{CONCLUSION}

The main purpose of this work is to represents the DGA analysis of power transformer using different control methods. The condition based analysis of DGA has developed using different control methods. The brief review is also described in this paper of all controlling methods. The simulation results of Matlab simulation has successfully done through Duval Triangle method as a conventional control method and ANN \& Bayer's classifier method developed as a machine learning control methods. The simulation results shows the better regulation of Machine learning methods compared to conventional control method.

\section{REFERENCES}

[1] Xiang Zhang, Gockenbach E., - Asset-management of transformers based on condition monitoring and standard diagnosis,\| IEEE Electrical Insulation Magazine, vol.24, no. 4, pp. 26-40, 2008.

[2] CIGRE Working Group 12.05, - An international survey on failures in large power transformers in service, $\|$ Electra, no. 88, pp. 21-47, 1983.

[3] J. P. Gibeault , J. K. Kirkup, -Early detection and continuous monitoring of dissolved key fault gases in transformers and shunt reactors, in Proc. Elect. Electronics Insul. Conf., Elect. Manufact. Coil Winding Conf., pp. 285-293, Sep. 1995.

[4] B. Pahlavanpour, A. Wilson, -Analysis of transformer oil for transformer condition monitoring, $\|$ in IEE Colloq. Engineer. Rev. Liquid Insul., pp. 1/1-1/5, Jan. 1997.

[5] B. Sparling, J. Aubin, -Field experience with multigas on-line monitoring of power transformers,"in Proc. IEEE Transmission Distrib. Conf., vol. 2, pp. 895-900, April 1999.

[6] B. Sparling, - Transformer monitoring and diagnostics, $\|$ Proceeding of IEEE Power Engineer. Society Winter Power Meeting, vol.2, New York, pp. 978-980, 1999.

[7] J. Lapworth, -A novel approach (scoring system) for integrating dissolved gas analysis results into a life management system, in Conf. Record of IEEE Int. Symp. Elect. Insul., pp. 137-144, April 2002.

[8] J. Sabau, L. Silberg, Paul Vaillancourt, - The impact of oil decay on gassing and reliability of aging power transformers, $\|$ in Annual Reprt Conf. Elect. Insul. Dielect. Phenomena, pp. 408-411, Oct. 2002.

[9] A. Shahsiah, R. C. Degeneff, -A new dynamic model for propagation of characteristic gases in transformer oil-cellulose structures due to temperature variations, $\|$ in Annual Report Conf. Elect. Insul. Dielect. Phenomena, pp. 269-272, Oct. 2005.

[10] J. Sabau, R. Stokhuyzen, - The side effects of gassing in transmission power transformers, $\|$ in Annual Report Conf. Elect. Insul .Dielect. Phenomena, vol. 1, pp. 264-267, Oct. 2000.

[11] R. Sans, John., K. Muge Bilgin, J. Joseph, - Large -scale survey of furanic compounds in operating transformers and lifell, Proc. of 1998 IEEE international symposium on electrical insulation, Arlington, USA, 543-553, June 7-10, 1998.

[12] R. Blue, D. Uttamchandani, O. Farish, -A novel solid state material for furfuraldehyde detection, $\|$ IEEE transactions on Dielectrics and electrical insulation, vol. 4, no.3, 341-343, 1997.

[13] R. B. Harrison, -Detection, determination and identification of furfuraldehyde in hydrocarbon oil, „l Analyst, 88, 644-646, 1963.

[14] Y. Han, Y. H. Song -Condition monitoring techniques for electrical equipments-A literature survey,\| IEEE Transactions on Power delivery, Vol.17, pp.4-13, 2003.

[15] M. Kohtoh, S. Kaneko, S. Okabe, T. Amimoto, -Ageing effect on electrical characteristics of insulating oil in field transformer,\| IEEE Transactions on Dielectrics and Electrical Insulation, vol.166, pp.1698-1706, 2009.

[16] M. Kohtoh, Genyo, S. Okabe, -Transformer Insulating oil characteristic changes observed using accelerated degradation in consideration of field transformer conditions,\| IEEE Transactions on Dielectrics and Electrical Insulation, Vol.18, pp.808-818, 2010.

[17] Syed Islam, Abus Siada, Lai Pin Sin, - Remnant Life estimation of Power transformer using oil UV-Vis Spectral response,\| IEEE International conference on Power systems, pp.15-18, March 2009. 